\title{
Abdominal Wall Endometriosis as Endometrioma-Cutaneous Fistula: A Case Report
}

\author{
Oluyemisi A. Adeyemi' ${ }^{1}$, Creighton L. Edwards', Thomas M. Wheeler², \\ Shannon M. Hawkins ${ }^{1 *}$ \\ ${ }^{1}$ Department of Obstetrics \& Gynecology, Baylor College of Medicine, Houston, USA \\ ${ }^{2}$ Department of Pathology \& Immunology, Baylor College of Medicine, Houston, USA \\ Email: shannonh@bcm.edu
}

Received 26 July 2014; revised 20 August 2014; accepted 16 September 2014

Copyright (C) 2014 by authors and Scientific Research Publishing Inc.

This work is licensed under the Creative Commons Attribution International License (CC BY). http://creativecommons.org/licenses/by/4.0/

c) (i) Open Access

\begin{abstract}
Endometriosis outside the pelvic cavity is rare, but its most common extra-pelvic location is the abdominal wall, occurring most frequently after cesarean delivery. Fistula tracks through these lesions in the abdominal wall to the uterus are rare. However, a fistula between abdominal wall endometriosis to an endometrioma has not been reported. A 46-year-old multigravid woman presented with complaint of cyclical pain and bleeding from her cesarean delivery scar and pelvic pressure. Computed tomography revealed a complex, $16-\mathrm{cm}$ left adnexal mass. Intraoperatively, a fistulous tract connecting a large endometrioma in the abdominal-pelvic cavity to the skin was noted and wide local excision of this track was performed in conjunction with aggressive surgical management of endometriosis throughout the pelvis. Pathologic analysis of the resected specimen confirmed the diagnosis. Although rare, endometrioma-cutaneous fistula should be included in the differential diagnosis of suspected abdominal wall endometriosis with concurrent adnexal mass for appropriate surgical planning.
\end{abstract}

\section{Keywords}

Endometrioma, Fistula, Abdominal Wall Endometriosis, Surgical Management

\section{Introduction}

Endometriosis is a gynecologic condition in which cells from the lining of the uterus are found outside the ute-

${ }^{*}$ Corresponding author.

How to cite this paper: Adeyemi, O.A., Edwards, C.L., Wheeler, T.M. and Hawkins, S.M. (2014) Abdominal Wall Endometriosis as Endometrioma-Cutaneous Fistula: A Case Report. Open Journal of Obstetrics and Gynecology, 4, 832-835. 
rine cavity, most common location is in the pelvis. Extra-pelvic endometriosis is rare, and its true prevalence is unknown given its lack of formal epidemiological study [1]. It has been reported to occur in nearly all body cavities and organs but its most common location is the abdominal wall [2]. Endometriosis in the abdominal wall, usually in the vicinity of a prior abdominal surgery, occurs most frequently after incision of a gravid uterus [2]-[5]. Characteristic presentation is of a painful, palpable mass with cyclic bleeding or discharge and worsening of pain and bleeding with menses [2] [6]. Imaging findings are usually non-specific with ultrasound-guided fine needle aspiration providing more definitive diagnosis. Treatment options include medical or surgical management [7] [8]. We reported here our experience with the surgical and pathologic diagnosis of a fistulous track between a pelvic endometrioma and abdominal wall endometriotic lesion in a previous cesarean delivery scar that was surgically treated resulting in complete resolution of the fistulous tract.

\section{Case Presentation}

A 46-year-old woman, gravida 3 para 3, was referred to clinic for a pelvic mass and a mass in her abdominal wall. The patient had a previous cesarean delivery for breech presentation complicated by a superficial postoperative wound infection 7 years prior. The abdominal wall mass was included in her CD scar and produced cyclic bleeding and increased pain with menstruation that had been going on for 2.5 years. Review of symptoms revealed a history of chronic pelvic pain, dyspareunia, increasing abdominal girth, urinary splinting, and dribbling. Pelvic ultrasound 7 months prior to clinic visit revealed a $2.5-\mathrm{cm}$ complex, left ovarian cyst and a 3.7-cm left ovarian heterogeneous structure likely representing a dermoid and a $5.8 \mathrm{~cm}$ complex right adnexal mass.

Physical examination revealed a vertical abdominal surgical scar with a pinpoint hole at the most superior aspect, with moderate amount of brown discharge noted around this skin defect. The abdomen was distended by the mass, extending $10 \mathrm{~cm}$ above the umbilicus. On speculum exam, normal vaginal mucosa was noted, but the cervix could not be visualized due to the abdominal mass effect displacing the cervix. Imaging was repeated to determine the presence of ascites and need for referral to gynecology oncology.

Abdominal and pelvic ultrasound revealed a $17.8 \mathrm{~cm} \times 9.6 \mathrm{~cm} \times 14.2 \mathrm{~cm}$ complex mass arising from the right adnexa and a $7.1 \mathrm{~cm} \times 7.1 \mathrm{~cm} \times 6.3 \mathrm{~cm}$ complex mass in the left adnexa. Computed tomography scan revealed a $16.6 \mathrm{~cm} \times 16.2 \mathrm{~cm} \times 13 \mathrm{~cm}$ multi-lobulated and complex cystic structure in the left adnexa displacing the bladder, uterus, right ovary, sigmoid colon, and the rectum. An enhancing mass within the cesarean delivery surgical scar was suggestive of endometriosis (Figure 1). Imaging did not show ascites, and serum CA-125 was 69.5 units/mL.

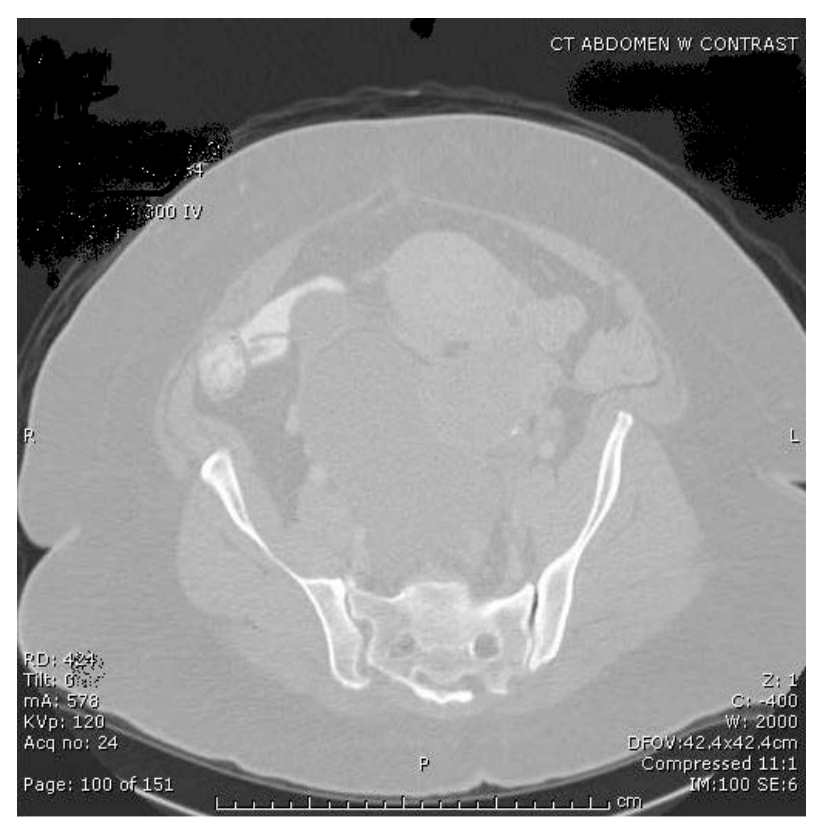

Figure 1. Computed Tomography scan showing multi-lobulated pelvic mass. 




Figure 2. Microscopic findings. 40× view of surgical specimen revealing endometriosis. The surgical specimen was fixed in $10 \%$ buffered formalin and routinely processed. Hematoxylin and eosin sections were prepared from the formalin-fixed, paraffin-embedded (FFPE) blocks. Serial sections $5 \mu \mathrm{m}$ thick were cut from the FFPE blocks.

The patient was taken to the operating room for excision of suspected abdominal wall endometriosis, exploratory laparotomy, and TAH-BSO. Upon beginning the exploratory laparotomy skin incision, a large ventral wall hernia, containing omentum and multiple pockets of endometriomas, was discovered within a hernia sac. This fistulous track from the skin continued through the subcutaneous fat, fascia, and into the large firm mass that was part of the right adnexa, a 7-cm diameter endometrioma. The defect in the fascia was approximately 5 $\mathrm{cm}$.

With gynecologic oncologic surgical expertise, the patient underwent a successful TAH-BSO with extensive enterolysis, wide local excision of abdominal wall endometriosis, and ventral herniorrhaphy. The specimen was submitted entirely for histologic examination; pathology revealed endometriosis throughout all pelvic organs, the hernia sac, and the abdominal wall (Figure 2). The patient had no postoperative complications, is free of pelvic pain, and has no urinary complaints.

\section{Discussion}

The strict definition of a fistula is a connection between two epithelium-lined organs. Fistulous tracks between the skin and reproductive organs are rare. While the literature contains several case reports of utero-cutaneous fistulas [4] [9]-[13], there is only one case report of utero-cutaneous fistula in women with endometriosis [10]. Thus, endometriosis does not seem to be a risk factor for developing utero-cutaneous fistulas. Common risk factors for developing utero-cutaneous fistula include surgical site infections, multiple previous abdominal surgeries, and poor wound closure including wound dehiscence [9] [10] [14].

Since the endometriotic cyst is lined with epithelium, this could be called an "endometrioma-cutaneous fistula”. However, an endometrioma is not an organ, and thus, this should technically be called a fistulous track of endometriosis. Here we report the first case of a fistulous track between a large pelvic endometrioma and the anterior abdominal wall, near the umbilicus that was treated with expert and aggressive surgical management with significant patient satisfaction. To date, there are no other case reports regarding medical or surgical management of this type of fistulous tract. Common sense should dictate that the size of the fistula and desire for future fertility be considered when deciding upon treatment options. For aggressive surgical management, the appropriate surgical team should include surgeons skilled in gynecologic surgery as well as herniorrhaphy.

\section{Financial Disclosure}

The authors did not report any potential conflicts of interest.

\section{References}

[1] Giannella, L., La Marca, A., Ternelli, G. and Menozzi, G. (2010) Rectus Abdominis Muscle Endometriosis: Case Re- 
port and Review of the Literature. Journal of Obstetrics and Gynaecology Research, 36, 902-906. http://dx.doi.org/10.1111/j.1447-0756.2010.01236.x

[2] Hensen, J.H., Van Breda Vriesman, A.C. and Puylaert, J.B. (2006) Abdominal Wall Endometriosis: Clinical Presentation and Imaging Features with Emphasis on Sonography. American Journal of Roentgenology, 186, 616-620. http://dx.doi.org/10.2214/AJR.04.1619

[3] Taff, L. and Jones, S. (2002) Cesarean Scar Endometriosis. A Report of Two Cases. The Journal of Reproductive Medicine, 47, 50-52.

[4] Dragoumis, K., Mikos, T., Zafrakas, M., et al. (2004) Endometriotic Uterocutaneous Fistula after Cesarean Section. A Case Report. Gynecologic and Obstetric Investigation, 57, 90-92. http://dx.doi.org/10.1159/000075384

[5] Dwivedi, A.J., Agrawal, S.N. and Silva, Y.J. (2002) Abdominal Wall Endometriomas. Digestive Diseases and Sciences, 47, 456-461. http://dx.doi.org/10.1023/A:1013711314870

[6] Honore, G.M. (1999) Extrapelvic Endometriosis. Clinical Obstetrics and Gynecology, 42, 699-711. http://dx.doi.org/10.1097/00003081-199909000-00021

[7] Patterson, G.K. and Winburn, G.B. (1999) Abdominal Wall Endometriomas: Report of Eight Cases. The American Journal of Surgery, 65, 36-39.

[8] Nissotakis, C., Zouros, E., Revelos, K., et al. (2010) Abdominal Wall Endometrioma: A Case Report and Review of the Literature. AORN Journal, 91, 730-742. http://dx.doi.org/10.1016/j.aorn.2010.01.014

[9] Gupta, S.K., Shukla, V.K., Varma, D.N., et al. (1993) Uterocutaneous Fistula. Postgraduate Medical Journal, 69, 822-823. http://dx.doi.org/10.1136/pgmj.69.816.822

[10] Thubert, T., Denoiseux, C., Faivre, E., et al. (2012) Combined Conservative Surgical and Medical Treatment of a Uterocutaneous Fistula. Journal of Minimally Invasive Gynecology, 19, 244-247. http://dx.doi.org/10.1016/j.jmig.2011.10.010

[11] Seyhan, A., Ata, B., Sidal, B., et al. (2008) Medical Treatment of Uterocutaneous Fistula with Gonadotropin-Releasing Hormone Agonist Administration. Obstetrics Gynecology, 111, 526-528. http://dx.doi.org/10.1097/01.AOG.0000281670.94265.5c

[12] Shukla, D., Pandey, S., Pandey, L.K., et al. (2006) Repair of Uterocutaneous Fistula. Obstetrics Gynecology, 108, 732733. http://dx.doi.org/10.1097/01.AOG.0000188067.74163.40

[13] Sonmezer, M., Sahincioglu, O., Cetinkaya, E., et al. (2009) Uterocutaneous Fistula after Surgical Treatment of an Incomplete Abortion: Methylene Blue Test to Verify the Diagnosis. Archives of Gynecology and Obstetrics, 279, 225227. http://dx.doi.org/10.1007/s00404-008-0683-7

[14] Mintz, N. and Gaines, J.A. (1951) Endometriosis in a Laparotomy Scar; Report of a Case with Utero-Abdominal Fistula. Journal of the Mount Sinai Hospital, New York, 17, 613-617. 
Scientific Research Publishing (SCIRP) is one of the largest Open Access journal publishers. It is currently publishing more than 200 open access, online, peer-reviewed journals covering a wide range of academic disciplines. SCIRP serves the worldwide academic communities and contributes to the progress and application of science with its publication.

Other selected journals from SCIRP are listed as below. Submit your manuscript to us via either submit@scirp.org or Online Submission Portal.
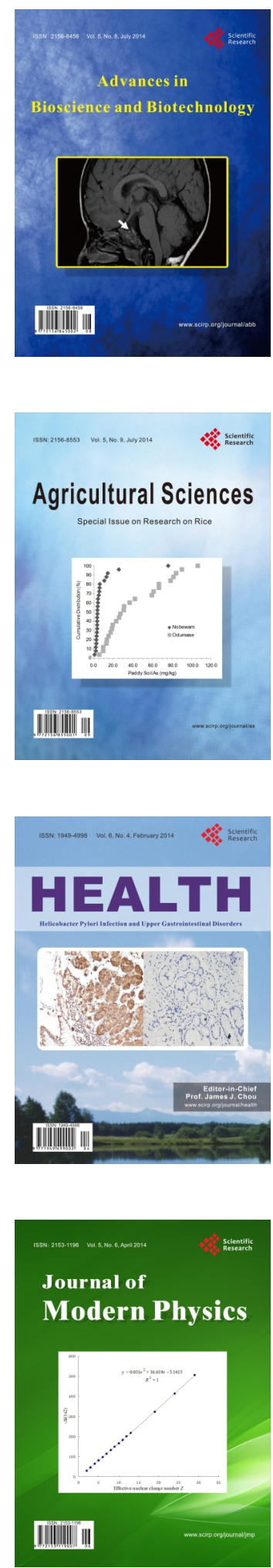
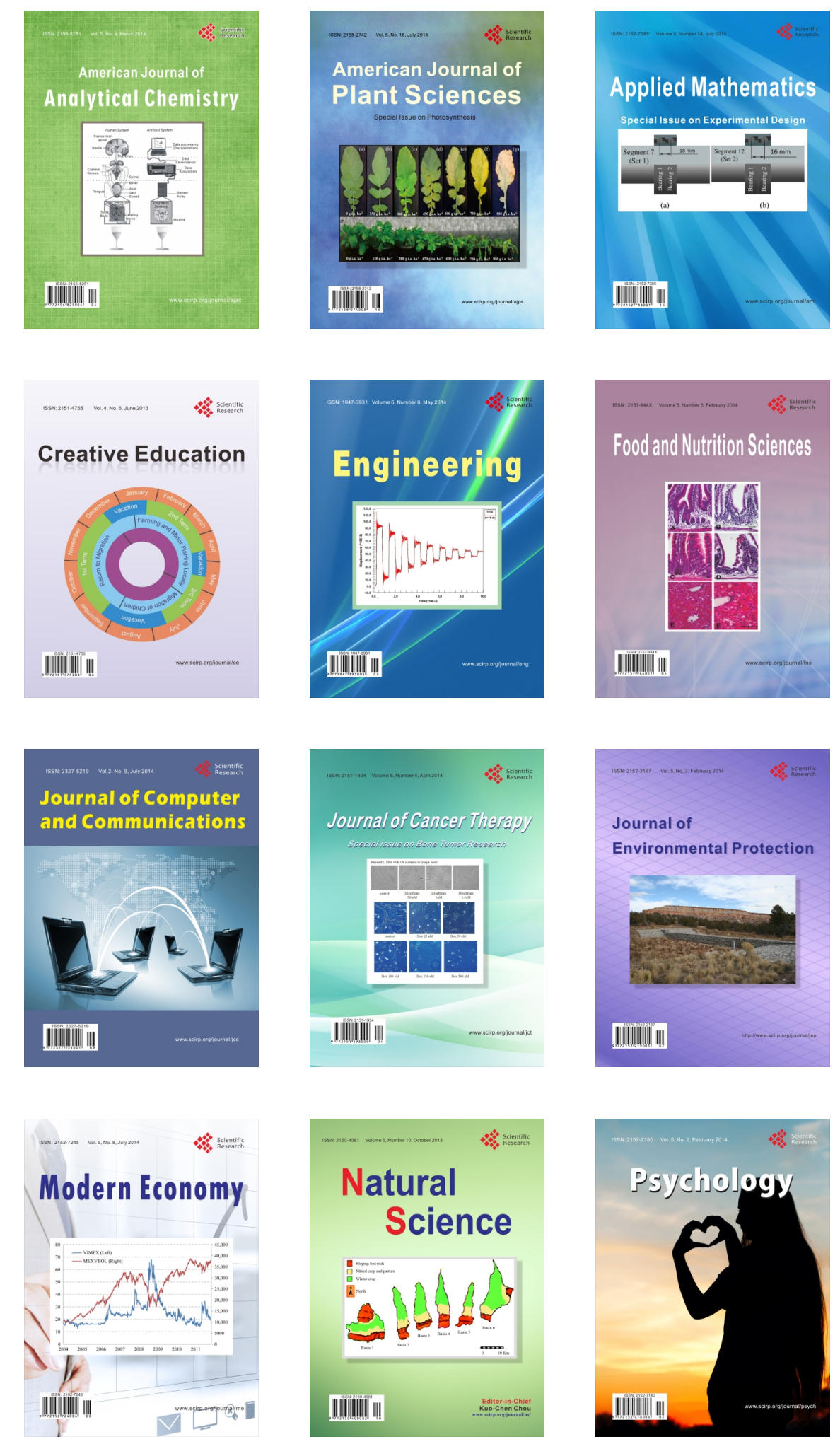